\title{
Magnitude Scaling Factors in Liquefaction Triggering Procedures
}

\author{
by \\ Ross W. Boulanger ${ }^{a}$ \\ (Corresponding author: rwboulanger@ucdavis.edu)
}

I. M. Idriss ${ }^{b}$

${ }^{a}$ Professor, Department of Civil and Environmental Engineering, University of California, Davis, USA

${ }^{\mathrm{b}}$ Professor Emeritus, Department of Civil and Environmental Engineering, University of California, Davis, USA

Submitted to SDEE

Special Issue: Liquefaction in NZ/Japan

November 2014 


\section{ABSTRACT}

A revised magnitude scaling factor (MSF) relationship for CPT-based and SPT-based liquefaction triggering analyses is presented in this paper. The revised MSF relationship incorporates functional dependency on the soil characteristics [represented by clean sand equivalent penetration resistances in the present form] as well as on earthquake magnitude. The revisions in MSF are based on the examination of cyclic testing results for a broad range of soil types and densities, analyses of strong ground motion records to develop relationships for the equivalent number of loading cycles for different soil properties, and the synthesis of those results into an MSF relationship suitable for implementation in practice. A separate study (Boulanger and Idriss 2014) showed that use of the revised MSF relationship in CPT-based and SPT-based liquefaction triggering procedures is well-supported by the case history databases. Other factors known to fundamentally influence the MSF are discussed.

Key Words: $\quad$ earthquakes; liquefaction triggering; magnitude scaling factor.

\section{Introduction}

Magnitude scaling factor (MSF) relationships are used in field-based [Standard Penetration Test (SPT), Cone Penetration Test (CPT), and shear wave velocity, $\mathrm{V}_{\mathrm{s}}$ ] liquefaction triggering correlations to approximately account for how the characteristics of the irregular cyclic loading produced by different magnitude earthquakes affect the potential for triggering of liquefaction. MSF relationships depend on the characteristics of both the imposed loading and the soil's response to loading, as expected for any type of fatigue problem. MSF relationships developed for sands (e.g., Seed et al. 1975, Liu et al. 2001, Green and Terri 2005, Idriss and Boulanger 2008) have mostly been developed using typical properties for clean sands, such that the MSF relationships do not include functional dependence on any soil property. The MSF relationship developed by Boulanger and Idriss (2007) for cyclic softening analyses of clays similarly used typical properties for clays and plastic silts, and thus also did not include functional dependence on any soil property. Cetin and Bilge (2012) introduced MSF relationships that depended on the failure criterion (strain or pore pressure ratio based) and dilatational response of the soil (which depends on relative density and overburden stress). Kishida and Tsai (2014) presented an MSF relationship which includes functional dependence on the soil parameter (b) which is the negative slope of the log-log relationship between cyclic resistance ratio (CRR) and number of uniform loading cycles to failure $(\mathrm{N})$. The strong effect of soil properties on MSF relationships is illustrated in Figures 1 and 2 showing the MSF relationships by Boulanger and Idriss (2007) and Kishida and Tsai (2014), respectively.

The purpose of the MSF relationship, as a functional component in a liquefaction triggering procedure, is to account for the primary influencing variables while maintaining sufficient simplicity for implementation in practice. Fundamentally, the MSF is known to be physically affected by numerous factors, including the earthquake source characteristics, distance from the site to the source, soil profile characteristics, and depth in the soil profile (e.g., Liu et al. 2001, Green and Terri 2005), but the inclusion of all dependencies may not be warranted in practice. The benefits of progressively including additional influencing variables in an MSF relationship can instead be evaluated by the degree to which it: (1) reduces bias or dispersion between the 
liquefaction case history data and the liquefaction triggering correlation, or (2) is considered important for extending the correlation beyond the range of conditions covered by the case history data.

This paper summarizes the development of an MSF relationship which includes functional dependence on an index of the soil properties in addition to the earthquake magnitude M. The following sections describe the procedure used for weighting of irregular loading cycles, a review of cyclic testing literature to evaluate how the parameter $b$ varies with soil type or other factors, the effect of the parameter $b$ on the equivalent number of loading cycles, and the synthesis of those results into an MSF relationship suitable for implementation in practice. The revised MSF relationship was used in the processing of the CPT-based and SPT-based case histories and found to be well-supported by the case history data; additional details on the development of the revised MSF relationship and the SPT and CPT based liquefaction triggering procedures are provided in Boulanger and Idriss (2014).

\section{Weighting of Irregular Loading Cycles}

Seed et al. (1975) introduced a weighting scheme for converting an irregular cyclic loading history to some equivalent number of uniform loading cycles. This weighting scheme, which has been in use since then, is similar to the Palmgren-Miner cumulative damage hypothesis (Palmgren 1924, Miner 1945) for high-cycle fatigue of metals. A key parameter in these procedures is the slope of the relationship between the CRR and number of uniform loading cycles to failure $(\mathrm{N})$. The CRR versus $\mathrm{N}$ relationship, over the range of $\mathrm{N}$ values important to earthquake loading, can often be reasonably approximated using a power law as,

$$
C R R=a \cdot N^{-b}
$$

where $b$ is the fitting parameter describing the slope of the relationship. For two individual stress cycles having magnitudes $\mathrm{CSR}_{\mathrm{A}}$ and $\mathrm{CSR}_{\mathrm{B}}$, the relative number of cycles to cause failure at these two stress ratios can be obtained from the above relationship as,

$$
\frac{N_{A}}{N_{B}}=\left(\frac{C S R_{B}}{C S R_{A}}\right)^{1 / b}
$$

The damage from one cycle of stress at CSRB would then be equivalent to the damage from $\mathrm{X}_{\mathrm{A}}$ cycles at CSRA if their numbers of cycles are an equal fraction of the number of cycles to failure at their respective CSRs. This leads to the expression,

$$
X_{A}=\left(\frac{C S R_{B}}{C S R_{A}}\right)^{1 / b}\left(1 \text { cycle at } C S R_{B}\right)
$$

This expression can be used to convert individual stress cycles into an equivalent number of uniform cycles at some reference stress level. The total number of equivalent uniform cycles at a reference stress level can then be determined for a wide range of earthquake ground motions, from 
which a representative number of equivalent uniform cycles can be obtained for a given earthquake magnitude (NM). The MSF can then be determined as,

$$
M S F=\frac{C S R_{M}}{C S R_{M=7.5}}=\left(\frac{N_{M=7.5}}{N_{M}}\right)^{b}
$$

where $\mathrm{N}_{\mathrm{M}=7.5}$ is the number of uniform cycles for $\mathrm{M}=7.5, \mathrm{CSR}_{\mathrm{M}}$ is the CSR induced by an earthquake of magnitude $M$, and $\mathrm{CSR}_{\mathrm{M}=7.5}$ is the equivalent $\mathrm{CSR}$ for $\mathrm{M}=7.5$.

The effect of $b$ on the MSF relationships was previously illustrated in Figures 1 and 2 . The MSF relationship derived by Idriss (1999) for sands used $b=0.34$ based on cyclic test data by Yoshimi et al. (1984) for samples of Niigata sand obtained using frozen sampling techniques. The MSF relationship by Boulanger and Idriss (2007) for clays and plastic silts used $b=0.135$ for clays and plastic silts based on a compilation of cyclic testing data. The smaller $b$ value for clays and plastic silts results in a much flatter MSF relationship than was obtained for sands, as shown in Figure 1.

The MSF relationships by Kishida and Tsai (2014) in Figure 2 can be compared to those in Figure 1. The Kishida-Tsai MSF relationships are based on analyses of more than 3500 ground motion records for site class D conditions from the PEER strong ground motion database and include functional dependence on the peak ground acceleration, a spectral ratio parameter describing the shape of the acceleration response spectra, the earthquake magnitude, the parameter $b$, and the period of the soil layer. The Kishida-Tsai MSF curves shown in Figure 2 are based on a strike-slip earthquake, a peak ground acceleration of $0.20 \mathrm{~g}$, and the expected value for the spectral shape based on a ground motion prediction equation. The Kishida-Tsai MSF for $b=0.15$ is in good agreement with the Boulanger-Idriss MSF for the similar value of $b=0.135$. The Kishida-Tsai MSF for $b=0.35$ is a bit flatter than the Idriss MSF for $b=0.34$.

The MSF relationships in Figures 1 and 2 are based on a high-cycle fatigue framework for computing equivalent numbers of uniform loading cycles, whereas a low-cycle fatigue framework is conceptually preferable for evaluating liquefaction triggering in short duration motions (e.g., Green and Terri 2005). Nonetheless, the results obtained by Kishida and Tsai (2014) as presented in Figure 2 were considered sufficiently accurate for the purposes of the present study given the larger uncertainties associated with the ground motion characteristics and the estimation of any specific soil's fatigue characteristics (as represented by the parameter b) in practice.

\section{Experimental Data for $b$ Values}

For clean sands, experimental data compiled from the literature shows that the $b$ value tends to increase with increasing CRR (for the same number of cycles to failure) or relative density. Results of cyclic tests on sands obtained using frozen sampling techniques are summarized in Figures 3 and 4. The data obtained by Yoshimi et al. (1989) for five sites show b values of 0.34 for the densest sand (curve D in Figure 3), values of $0.41,0.27$ and 0.13 for the sands with intermediate strength or denseness (curves C3, C1, and B), and a value of 0.15 for the weakest or loosest sand (curve A). The sand from Duncan Dam (Pillai and Stewart 1994, Figure 3) also has 
very low cyclic strength and the lowest $b$ value of 0.08 . The data obtained by Okamura et al. (2003; Figure 4) at a site treated by sand compaction piles similarly show a consistent variation with denseness of the sand; the densest and strongest sands had $b$ values of $0.45,0.50$, and 0.54 , whereas the looser and weaker sands had $b$ values of $0.13,0.15$, and 0.21 .

Cyclic tests on reconstituted samples of clean sand show similar trends to those from frozen samples. For example, the cyclic tests by Silver et al. (1976) for $D_{R}=60 \%$ Monterey sand show intermediate cyclic strengths with a $\mathrm{b}$ value of 0.22 , whereas the cyclic tests by Toki et al. (1986) for $D_{R}=50 \%$ Toyoura sand show much smaller cyclic strengths with a smaller b value of 0.10 . The cyclic direct simple shear tests by Boulanger and Seed (1995) for reconstituted sand show b values of 0.17 and 0.15 at $D_{R}$ of $35 \%$ and $45 \%$, respectively, but a higher b value of 0.27 for $D_{R}$ of 55\%. The cyclic shaking table tests by DeAlba et al. (1976) for reconstituted sand at $D_{R}$ ranging from $54 \%$ to $90 \%$ are a notable exception, in that they show b values of 0.21 to 0.25 without any apparent trend with $\mathrm{DR}_{\mathrm{R}}$

Cyclic triaxial and cyclic torsional shear tests on Toyoura and Sengenyama sands by Tatsuoka et al. (1986) demonstrate a number of other factors affecting the shape and slope of the CRR versus $\mathrm{N}$ curves. For example, their results for cyclic torsional shear tests and cyclic triaxial tests indicated that the cyclic triaxial tests tended to produce steeper curves at lower numbers of cycles than were obtained in the cyclic torsional shear tests. This trend is, however, opposite to Seed et al.'s (1975) observation that cyclic triaxial tests gave flatter curves than obtained using simple shear tests. The results of Tatsuoka et al. also showed that the slope increased with increasing values for the failure strain used to define the CRR, which suggests that magnitude duration effects may be different when evaluating the potential for large strains and deformations versus evaluating the onset of triggering alone (e.g., a single-amplitude shear strain of about 3\%). Furthermore, their results showed that the cyclic strength curves became more strongly curved at low numbers of cycles as the relative density of the specimens increased and the failure strain criterion increased. The latter observation is illustrated in Figure 5 for cyclic torsional shear tests on Sengenyama sand air pluviated to relative densities ranging from $40-95 \%$ and plotted for a failure strain criterion of $15 \%$ double-amplitude shear strain. The curves for the denser specimens are more strongly curved than a power law fit can approximate, showing that the $b$ parameter will depend on the range of cycles over which it is fitted (the average values listed on the figure are based on a power fit over the range of the data provided). Lastly, these and other results by Tatsuoka et al. (1986) also show effects of the sample preparation method, the consolidation stress conditions, and the specific sand being tested.

Cyclic tests on reconstituted silty sands with nonplastic fines have also shown similar trends. Cyclic triaxial tests on Ottawa sand with 0, 5, 10, and 15\% nonplastic fines by Carraro et al. (2003) showed $\mathrm{b}$ values ranging from 0.09 to 0.44 , with the $\mathrm{b}$ values generally increasing with increasing value of CRR (for the same number of cycles to failure) regardless of FC (Figure 6). Similarly, cyclic triaxial tests on reconstituted Fitzgerald bridge sand with 1, 10, 20, and 30\% nonplastic fines by Rees (2010) showed b values ranging from 0.22 to 0.4 , with the $b$ values generally increasing with increasing level of CRR (for the same number of cycles to failure) regardless of FC. Cyclic torsional shear tests by Towhata et al. (2013) on loose Tokyo Bay sand ejecta with 0, 10, 20, 30, 40,60 , and $80 \%$ nonplastic fines prepared with similar compaction energies showed $\mathrm{b}$ values of about 0.07-0.23 with no apparent trend with respect to FC (Figure 7). Cyclic direct simple shear 
tests Dahl et al. (2014) on undisturbed samples of a normally consolidated, silty sand and sandy silt stratum $(\mathrm{FC}=35-77 \%)$ showed a $\mathrm{b}$ value of about 0.14 .

Cyclic tests on reconstituted clayey sands with low-plasticity fines have shown similar trends as well. Cyclic tests by Kokusho et al. (2012) on a sand with $0,5,10$, and $20 \%$ silty and clayey fines $(\mathrm{PI}=6)$ produced $\mathrm{b}$ values of about 0.08 to 0.13 when loose $\left(\mathrm{D}_{\mathrm{R}} \approx 30 \%\right)$ and about 0.17 to 0.28 when dense $\left(\mathrm{D}_{\mathrm{R}} \approx 70 \%\right)$. Cyclic triaxial tests by Kondoh et al. (1987) on Sengenyama sand with 30\% Kaolin prepared at overconsolidation ratios (OCR) of 1, 2, and 4 showed b values of $0.14,0.22$, and 0.28 , respectively; the increase of $b$ value with increasing OCR may reflect increases in density as well as the effects of OCR. Cyclic tests by Park and Kim (2013) on sand with $\mathrm{FC}=10 \%$ with the fines having PI values of $8,18,50$, and 377 produced $b$ values of about 0.14 for loose specimens and about 0.19 for dense specimens. Isotropically and anisotropically consolidated cyclic triaxial tests by Hyde et al. (2006) on sedimented specimens of a low plasticity silt (powdered limestone; PI =6) showed a b value of 0.23 for cases with shear stress reversal and 0.28 for cases with no shear stress reversal.

Dahl (2011) compiled cyclic test data for a wide range of plastic fine-grained soils, from which the $b$ values were examined for any trend with regard to FC or fines PI. These data show considerable scatter, but the general trend is that the average $b$ value is between 0.1 and 0.135 for FC from 45 to $100 \%$ and PI from 2 to 30.

The preceding examples of laboratory test data illustrate how the slopes of the cyclic strength curves can vary with denseness (or state), FC, fines plasticity, failure strain, number of cycles to failure (i.e., slope is not constant), and test device. There is significant variability in the slopes obtained in these various studies and in the observed effects of each of the above factors. The dominant factor does, however, appear to be the denseness (or state) of the soil, and thus its influence on MSF relationships is explored further in the following sections.

\section{Effect of $b$ Value on the Number of Equivalent Loading Cycles and MSF}

The effect of $b$ on the number of equivalent uniform loading cycles is illustrated in Figure 8 for earthquakes with $M \approx 7.5$. This figure shows $\mathrm{N}_{M}=7.5$ computed for $b$ values of 0.06 to 0.40 for a set of 42 motions at category D sites with peak ground accelerations (PGA) of 0.11 to $0.51 \mathrm{~g}$ during $M=7.3-7.6$ earthquakes. At any given value of $b$, the $\mathrm{N}_{M}=7.5$ values varied by factors of 2 to 3. The geometric mean values for $\mathrm{N}_{M}=7.5$ were relatively constant at about 15 for $b$ values of 0.2 to 0.5 , and then increased rapidly for $b$ values progressively smaller than about 0.2 . Also shown on this figure is the trend in mean values obtained by Kishida and Tsai (2014) based on their analyses of more than 3500 ground motion recordings at category D sites from the PEER strong ground motion database. These results, and those presented previously by Boulanger and Idriss (2007) and Dahl (2011), are in good agreement.

The maximum value that the MSF can obtain for a small magnitude earthquake (MSF $\max$ ) corresponds to the case where the motion is dominated by a single strong acceleration pulse. Such a pulse could be one-sided such that it corresponds to $1 / 2$ of a full cycle, or it could be symmetric so it corresponds to a full cycle. If this single pulse scenario is represented by $3 / 4$ of a cycle at its peak stress, then the equivalent number of uniform cycles at $65 \%$ of the peak stress would be, 


$$
N_{\text {min }}=\left(\frac{1.0}{0.65}\right)^{1 / b}\left(\frac{3}{4} \text { cycle }\right)
$$

This minimum number of equivalent cycles can be used to compute the upper limit on MSF as,

$$
M S F_{\text {max }}=\left(\frac{N_{M=7.5}}{N_{\text {min }}}\right)^{b}
$$

The value of MSFmax for a given value of $\mathrm{b}$ can be determined using the above equations with the $\mathrm{N}_{M=7.5}$ results from Figure 8. The resulting relationship between $\mathrm{MSF}_{\max }$ and $\mathrm{b}$ is shown in Figure 9. The values of $\mathrm{MSF}_{\max }=1.8$ at $\mathrm{b}=0.34$ and $\mathrm{MSF}=1.09$ at $\mathrm{b}=0.135$ are consistent with the $\mathrm{MSF}_{\max }$ values derived for sand by Idriss (1999) and for clays and plastic silts by Boulanger and Idriss (2007), respectively, as shown previously in Figure 1. Idriss (1999) and Boulanger and Idriss (2007) assigned the $\mathrm{MSF}_{\max }$ value to $\mathrm{M}=5.25$ events, and so the MSF values at $\mathrm{M}=5.25$ from Kishida and Tsai's (2014) results in Figure 2 are also included on this figure for comparison. Kishida and Tsai's MSF $=5.25$ values become progressively smaller than the plotted MSF $\max$ values with increasing $\mathrm{b}$ value, for the reasons discussed previously.

The MSF relationships used by Idriss and Boulanger (2008), as shown in Figure 1, can be rewritten in a more general form as,

$$
M S F=1+\left(M S F_{\max }-1\right)\left(\frac{\exp \left(\frac{-M}{4}\right)-\exp \left(\frac{-7.5}{4}\right)}{\exp \left(\frac{-5.25}{4}\right)-\exp \left(\frac{-7.5}{4}\right)}\right)
$$

where they used $\mathrm{MSF}_{\max }=1.8$ for sand and $\mathrm{MSF}_{\max }=1.09$ for clay and plastic silt, and the form of the equation is based on $\mathrm{MSF}_{\max }$ occurring at $\mathrm{M}=5.25$. With the fixed terms expressed numerically, the above equation becomes,

$$
M S F=1+\left(M S F_{\max }-1\right)\left(8.64 \exp \left(\frac{-M}{4}\right)-1.325\right)
$$

This form of the MSF relationship, coupled with a relationship between $\mathrm{MSF}_{\max }$ (or MSFM=5.25) and $b$, allows generation of MSF curves for different values of $b$. For example, the MSF max versus b relationship shown in Figure 9 were used to generate the MSF curves shown in Figure 10. These MSF curves have slightly greater dependency on M (i.e., slightly steeper curves) than those by Kishida and Tsai (2014) shown previously in Figure 2.

\section{Relating MSF to Penetration Resistances}

The last step in deriving a revised MSF for CPT-based or SPT-based liquefaction triggering procedures requires relating the parameter $\mathrm{MSF}_{\max }$ (via the parameter $\mathrm{b}$ ) to some combination of soil characteristics (e.g., FC, PI), CPT parameters (e.g., qc1N, qc1Ncs, Ic), or SPT parameters (e.g., 
$\left.\left(\mathrm{N}_{1}\right)_{60},\left(\mathrm{~N}_{1}\right)_{60 \mathrm{cs}}\right)$. The experimental data reviewed in the previous section suggests that a key parameter affecting the parameter $\mathrm{b}$ is the dilatancy or dilation angle for the soil; i.e., denser and stronger soils have higher CRR values and greater $b$ values. This trend appears to hold independently of FC. The presence of fines causes CPT- and SPT-based triggering curves to shift leftward (or upward), as illustrated by the CPT-based correlation of Boulanger and Idriss (2014) shown in Figure 11, with this leftward/upward shift attributed primarily to the effects of the fines on the penetration resistance (Cubrinovski et al. 2010). Mathematically, the effect of fines has often been accounted for by adding a fines adjustment to the penetration resistance to obtain an equivalent clean sand penetration resistance that gives the same CRR value. For this reason, the parameters $\mathrm{q}_{\mathrm{c} 1 \mathrm{Ncs}}$ and $\left(\mathrm{N}_{1}\right)_{60 \mathrm{cs}}$ were preferred over $\mathrm{q}_{\mathrm{c} 1 \mathrm{~N}},\left(\mathrm{~N}_{1}\right)_{60}$, or $\mathrm{I}_{\mathrm{c}}$ as the indicator variables for dilatancy and b values; e.g., the sharp upward bends in the CRR correlations are attributed to sharp increases in dilatancy (and hence higher expected $b$ values) and these map better to $q_{c 1 N c s}$ and $\left(\mathrm{N}_{1}\right)_{60 \mathrm{cs}}$ than to $\mathrm{q}_{\mathrm{c} 1 \mathrm{~N}}$ or $\left(\mathrm{N}_{1}\right)_{60}$.

The MSFmax values computed for $\mathrm{b}$ values from the laboratory test data reviewed in the previous section is plotted versus equivalent values of q $1 \mathrm{Ncs}_{\mathrm{c}}$ in Figure 12 and equivalent $\left(\mathrm{N}_{1}\right)_{60 \mathrm{cs}}$ values in Figure 13. The equivalent $\mathrm{q}_{\mathrm{c} 1 \mathrm{Ncs}}$ and $\left(\mathrm{N}_{1}\right)_{60 \mathrm{cs}}$ values in these figures were determined as the values for which the applicable triggering correlation produces the same $C_{R}=7.5, \sigma^{\prime}=1$ value as obtained from the laboratory test data. This approach is consistent with the assumption of CPT or SPT based triggering correlations that those factors which affect penetration resistances also affect the cyclic strengths in reasonably proportional ways. The results of the cyclic laboratory tests were first converted to equivalent field conditions using the adjustment factors summarized in Idriss and Boulanger (2008). Alternative estimates for equivalent $\mathrm{q}_{\mathrm{c} 1 \mathrm{Ncs}}$ and $\left(\mathrm{N}_{1}\right)_{60 \mathrm{cs}}$ values were obtained through various correlations between soil characteristics and penetration resistances, but such approaches were difficult to apply to all laboratory data due to insufficient information for estimating penetration resistances and did not change the general trends or reduce the significant scatter observed between the MSFmax values and estimated penetration resistances. The MSF $\max$ values remain close to about 1.1 up to qc1Ncs values of about 40, after which they increase sharply with increasing $\mathrm{q}_{\mathrm{c} 1 \mathrm{Ncs}}$ or $\left(\mathrm{N}_{1}\right)_{60 \mathrm{cs}}$. The data points for field samples obtained using frozen sampling techniques and for reconstituted soil specimens are reasonably consistent given the significant scatter in the data.

The specification of relationship between $\mathrm{MSF}_{\max }$ and $\mathrm{q}_{\mathrm{c} 1 \mathrm{Ncs}}$ or $\left(\mathrm{N}_{1}\right)_{60 \mathrm{cs}}$ values is not well constrained by the data in Figures 12 and 13 alone, and thus a number of other factors were considered in guiding the form of these relationships. First, MSF $\max$ was set equal to 1.8 at $\mathrm{q}_{\mathrm{c} 1 \mathrm{Ncs}}$ $\approx 160$ and $\left(\mathrm{N}_{1}\right)_{60 \mathrm{cs}} \approx 28$ to be consistent with the clean sand relationship Idriss (1999) developed based on the frozen sampling test data for dense Niigata sands by Yoshimi et al. (1984). Second,

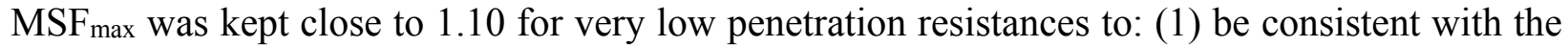
values expected for low-plasticity silts based on the b values compiled by Dahl (2011), and (2) not be smaller than the MSF max value of 1.09 developed for plastic fine-grained soils by Boulanger and Idriss (2007). Third, the scenario of a loose low-plasticity silt having a low penetration resistance was considered; e.g., for $\mathrm{q}_{\mathrm{c} 1 \mathrm{~N}}$ in the range of 20 , the resulting $\mathrm{q}_{\mathrm{c} 1 \mathrm{Ncs}}$ value would be about 70-80 (Figure 11) and this would produce an $\mathrm{MSF}_{\max }$ close to about 1.2, which was considered reasonable for this type of soil. Fourth, the adopted MSF $\max$ relationships were used to produce a family of curves showing CRR versus number of loading cycles for a range of penetration resistances, for the purpose of ensuring that the curves smoothly shift rather than pinch 
sharply together (further discussed and illustrated below). Fifth, the relationships between MSF max and $\mathrm{q}_{\mathrm{c} 1 \mathrm{Nos}}$ or $\left(\mathrm{N}_{1}\right)_{60 \mathrm{cs}}$ were developed to be consistent as illustrated in Figure 14 and described below. Sixth, the resulting MSF relationships were evaluated based on how well they reduced any apparent biases or misfits between the CPT-based and SPT-based case histories and their respective correlations (Boulanger and Idriss 2014). This process required several iterations, with each successive adjustment guided by consideration of all of the above factors.

The relationship between $\mathrm{MSF}_{\max }$ and $\mathrm{q}_{\mathrm{c} 1 \mathrm{Ncs}}$ or $\left(\mathrm{N}_{1}\right)_{60 \mathrm{cs}}$ values was re-examined using the ground motion regression results of Kishida and Tsai (2014) to describe the variation of MSF $=5.25$ with the parameter $b$. The results of this re-examination are plotted in Figure 15 and 16 showing

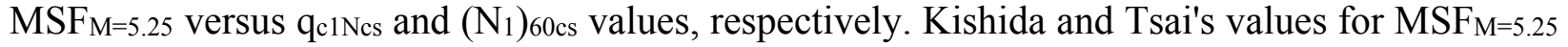
are smaller than the values of $\mathrm{MSF}_{\max }$ for the same $b$ value (Figure 9), and thus use of their relationship lowers the data points for the same penetration resistance.

The adopted relationships between MSF max, $\mathrm{q}_{c 1 N c s}$, and $\left(\mathrm{N}_{1}\right)_{60 c s}$ are given by,

$$
\begin{aligned}
& \operatorname{MSF}_{\text {max }}=1.09+\left(\frac{q_{C 1 N C S}}{180}\right)^{3} \leq 2.2 \\
& M_{\text {max }}=1.09+\left(\frac{\left(N_{1}\right)_{600 s 5}}{31.5}\right)^{2} \leq 2.2
\end{aligned}
$$

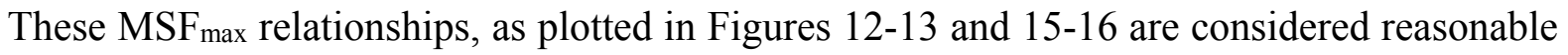
approximations of the available data. The consistency of the CPT-based and SPT-based forms is illustrated in Figure 14 showing their respective MSFmax values versus the values of

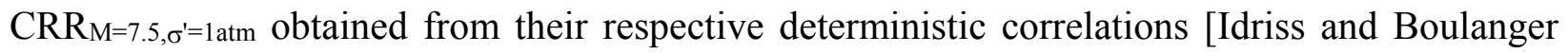
(2008) for the SPT, Boulanger and Idriss (2014) for the CPT].

The resulting MSF relationships for different values of $\mathrm{q}_{\mathrm{c} 1 \mathrm{Ncs}}$ and $\left(\mathrm{N}_{1}\right)_{60 \mathrm{cs}}$ are shown in Figure 17. As expected, the MSF for very low penetration resistances (loose soils) is relatively flat and the MSF for high penetration resistances (dense soils) is similar to those previously used for clean sands.

The revised MSF relationship in combination with the liquefaction triggering correlations defines the expected $\mathrm{CRR}-\mathrm{N}$ curves for sands at different penetration resistances. For example, curves of CRR versus $\mathrm{N}$ cycles are shown in Figure 18 for a range of qc1Ncs values. These curves are shown from 1 to 200 cycles to illustrate that the curves remain separated despite their differences in slopes; i.e., the curves will intersect at some extremely large number of loading cycles because they do not explicitly incorporate any strain threshold limits or lower limits on the CSR values below which liquefaction is not possible regardless of the number of loading cycles. This limitation is, however, not of practical significance for the current application.

The fit between the revised CPT-based and SPT-based liquefaction triggering correlations and their respective case history databases is shown in Boulanger and Idriss (2014). The revised MSF relationships were found to improve the degree of fit for both databases, providing support for 
assumed functional forms for this relationship. The case history data are not, however, sufficient to constrain the shape of the MSF relationships to any significant degree. In this regard, the inclusion of some dependency of the MSF on soil characteristics was an improvement over having no such dependency, even though the form of this dependency was necessarily guided by subjective judgments.

\section{Conclusions}

A revised MSF relationship for CPT-based and SPT-based liquefaction triggering analyses was described which incorporates functional dependency on the soil characteristics [using $\mathrm{q}_{\mathrm{c} 1 \mathrm{Ncs}}$ as the index for the CPT procedures and $\left(\mathrm{N}_{1}\right)_{60 \mathrm{cs}}$ for the SPT procedures] as well as on earthquake magnitude. The revised MSF relationship is based on the examination of cyclic testing results for a broad range of soil types and densities, analyses of strong ground motion records to develop relationships for the equivalent number of loading cycles for different soil properties (including the work of Kishida and Tsai 2014), and the development of an MSF correlation whose form was guided by a number of other considerations. The revised MSF relationship builds upon and utilizes findings from Idriss (1999), Boulanger and Idriss (2007), Dahl (2011), and Kishida and Tsai (2014).

The revised MSF relationship was found to improve the degree of fit between the revised CPTbased and SPT-based liquefaction triggering correlations and their respective case history databases (Boulanger and Idriss 2014). This improvement in fit with the liquefaction case histories provides support for having the MSF component of the liquefaction analysis framework include functional dependency on soil characteristics in addition to earthquake magnitude.

Additional studies are needed for further improving the models used to represent magnitude scaling effects in liquefaction triggering analyses, as these are important for extending the liquefaction triggering analyses to situations involving either small or large earthquake magnitudes. Improvements may come from refining the functional dependency on soil type (e.g., FC, fines plasticity, state) and failure criterion (see Cetin and Bilge 2012), or from improvements to the weighting function for irregular loading or the inclusion of function dependency on factors such as distance to the fault, directivity, site conditions, or depth in a soil profile (see Liu et al. 2001, Green and Terri 2005, Carter et al. 2013). For critical projects, future studies may also demonstrate the utility of site-specific adjustments, such as may be possible with advanced laboratory testing of undisturbed field samples to determine the soil parameter $\mathrm{b}$ in combination with detailed seismic hazard analyses to better define the loading.

\section{Acknowledgments}

Portions of the work presented herein were derived from studies supported by the California Department of Water Resources (DWR) and the National Science Foundation (grants CMMI1138203 and CMMI-1300518). Any opinions, findings, or recommendations expressed in this material are those of the authors and should not be interpreted as necessarily representing the official policies, either expressed or implied, of either organization. The authors' work benefited from discussions with Professors Misko Cubrinovski and Russell Green. The authors appreciate the above support and discussions. 


\section{References}

[] Boulanger RW, Idriss IM. Evaluation of cyclic softening in silts and clays. J. Geotechnical and Geoenvironmental Eng., ASCE, 2007, 133(6), 641-52.

[] Boulanger RW, Idriss IM. CPT and SPT based liquefaction triggering procedures. Report No. UCD/CGM-14/01, Center for Geotechnical Modeling, Department of Civil and Environmental Engineering, University of California, Davis, CA, 2014, 134 pp.

[] Boulanger RW, Seed RB. Liquefaction of sand under bi-directional monotonic and cyclic loading. Journal of Geotechnical Engineering, ASCE, 1995, 121(12), 870-878.

[] Carraro JAH, Bandini P, Salgado R. Liquefaction resistance of clean and nonplastic silty sands based on cone penetration resistance. Journal of Geotechnical and Geoenvironmental Engineering, ASCE, 2003, 129(11), 965-976.

[] Carter, L., Green, R., Bradley, B., and Cubrinovski, M. (2013). "The influence of near-fault motions on liquefaction triggering during the Canterbury earthquake sequence." New Zealand - Japan Workshop on Soil Liquefaction during Recent Large-Scale Earthquakes, Dec 2-3, University of Auckland, NZ.

[] Cetin KO, Bilge HT. Performance-based assessment of magnitude (duration) scaling factors. Journal of Geotechnical and Geoenvironmental Engineering, ASCE, 2012, 138: 324-334.

[] Cubrinovski M, Rees S, Bowman E. Effects of non-plastic fines on liquefaction resistance of sandy soils. Earthquake Engineering in Europe. Geotechnical, Geological, and Earthquake Engineering, Springer, 2010, Vol. 17, 125-144.

[] Dahl KR. Evaluation of seismic behavior of intermediate and fine-grained soils. Doctoral thesis, University of California, Davis, CA, 2011.

[] Dahl KR, DeJong JT, Boulanger RW, Pyke R, Wahl D. Characterization of an alluvial silt and clay deposit for monotonic, cyclic and post-cyclic behavior. Canadian Geotechnical Testing Journal, 2014, DOI: 10.1139/cgj-2013-0057.

[] DeAlba P, Seed HB, Chan CK. Sand liquefaction in large scale simple shear tests. J. Geotechnical Eng. Div., ASCE, 1976, 102(GT9), 909-27.

[] Green RA, Terri GA. Number of equivalent cycles concept for liquefaction evaluationsrevisited. J. Geotechnical and Geoenvironmental Eng., ASCE, 2005, 131(4), 477-88.

[] Hyde A, Higuchi T, Yasuhara K. Liquefaction, cyclic mobility, and failure of silt. Journal of Geotechnical and Geoenvironmental Engineering, ASCE, 2006, 132(6), 716-735. 
[] Idriss IM. An update to the Seed-Idriss simplified procedure for evaluating liquefaction potential, in Proceedings, TRB Workshop on New Approaches to Liquefaction, Publication No. FHWA-RD-99-165, Federal Highway Administration, January, 1999.

[] Idriss IM, Boulanger RW. SPT-based liquefaction triggering procedures. Report UCD/CGM-10/02, Department of Civil and Environmental Engineering, University of California, Davis, CA, 2010, 259 pp.

[] Idriss IM, Boulanger RW. Soil liquefaction during earthquakes. Monograph MNO-12, Earthquake Engineering Research Institute, Oakland, CA, 2008, 261 pp.

[] Kishida T, Tsai CC. Seismic demand of the liquefaction potential with equivalent number of cycles for probabilistic seismic hazard analysis. Journal of Geotechnical and Geoenvironmental Engineering, ASCE, 2014, 10.1061/(ASCE)GT.1943-5606.0001033.

[] Kokusho T, Ito Y, Nagao Y, Green AR. Influence of non/low-plastic fines and associated aging effects on liquefaction resistance. Journal of Geotechnical and Geoenvironmental Engineering, ASCE, 2012, 138(6), 747-756.

[] Kondoh M, Sasaki Y, Matsumoto H. Effect of fines contents on soil liquefaction strength (part 1). Proc. Annual Meeting of the Japanese Society of Soil Mechanics and Foundation Engineering (in Japanese), Public Works Research Institute, Ministry of Construction, Tsukuba, Japan, 1987.

[] Liu AH, Stewart JP, Abrahamson NA, Moriwaki Y. Equivalent number of uniform stress cycles for soil liquefaction analysis. J. Geotechnical and Geoenvironmental Eng., ASCE, 2001, 127(12), 1017-026.

[] Miner MA. Cumulative damage in fatigue. Transactions, ASME, 1945, 67, A159-A164.

[] Okamura M, Ishihara M, Oshita T. Liquefaction resistance of sand deposit improved with sand compaction piles. Soils and Foundations, Japanese Geotechnical Society, 2003, 43(5), 175-187.

[] Palmgren A. Die lebensdauer von kugella geru. ZVDI, 1924, 68(14), 339-341.

[] Park SS, Kim YS. Liquefaction resistance of sands containing plastic fines with different plasticity. Journal of Geotechnical and Geoenvironmental Engineering, ASCE, 2013, 139(5), 825-830.

[] Pillai VS, Stewart RA. Evaluation of liquefaction potential of foundation soils at Duncan Dam. Canadian Geotechnical Journal, 1994, 31, 951-966.

[] Rees SD. Effects of fines on the undrained behavior of Christchurch sandy soils. Ph.D. thesis, University of Canterbury, Christchurch, New Zealand, May, 2010, 300 pp. 
[] Seed HB, Idriss IM, Makdisi F, Banerjee N. Representation of irregular stress time histories by equivalent uniform stress series in liquefaction analyses. Report No. EERC 75-29, Earthquake Engineering Research Center, University of California at Berkeley, CA, 1975, October.

[] Silver ML, Chan CK, Ladd RS, Lee KL, Tiedemann DA, Townsend FC, Valera JE, Wilson JH. Cyclic triaxial strength of standard test sand. Journal of ASCE, 1976, 102, GT5, 511523.

[] Tatsuoka F, Ochi K, Fujii S, Okamoto M. Cyclic undrained triaxial and torsional shear strength of sands for different sample preparation methods. Soils and Foundations, JSSMFE, 1986, 26(3), 23-41.

[] Toki S, Tatsuoka F, Miura S, Yoshimi Y, Yasuda S, Makihara Y. Cyclic undrained triaxial strength of sand by a cooperative test program. Soils and Foundations, 1986, 26, 117-128.

[] Towhata I, Gunji K, Hernandez YA, Yamada S. Laboratory tests on cyclic undrained behavior of loose sand with cohesionless silt and its application to assessment of seismic performance of subsoil. New Zealand - Japan Workshop on Soil Liquefaction during Recent Large-Scale Earthquakes, Dec 2-3, University of Auckland, NZ, 2013, paper 8.

[] Yoshimi Y, Tokimatsu K, Kaneko O, Makihara Y. Undrained cyclic shear strength of a dense Niigata sand. Soils and Foundations, Japanese Society of Soil Mechanics and Foundation Engineering, 1984, 24(4), 131-45.

[] Yoshimi Y, Tokimatsu K, Hosaka Y. Evaluation of liquefaction resistance of clean sands based on high-quality undisturbed samples. Soils and Foundations, 1989, 29(1), 93-104.

[] Youd TL, Idriss IM, Andrus RD, Arango I, Castro G, Christian JT, Dobry R, Finn WDL, Harder LF, Hynes ME, Ishihara K, Koester JP, Liao SSC, Marcuson WF, Martin GR, Mitchell JK, Moriwaki Y, Power MS, Robertson PK, Seed RB, Stokoe KH. Liquefaction resistance of soils: summary report from the 1996 NCEER and 1998 NCEER/NSF workshops on evaluation of liquefaction resistance of soils, J. Geotechnical and Geoenvironmental Eng., ASCE, 2001, 127(10), 817-33. 


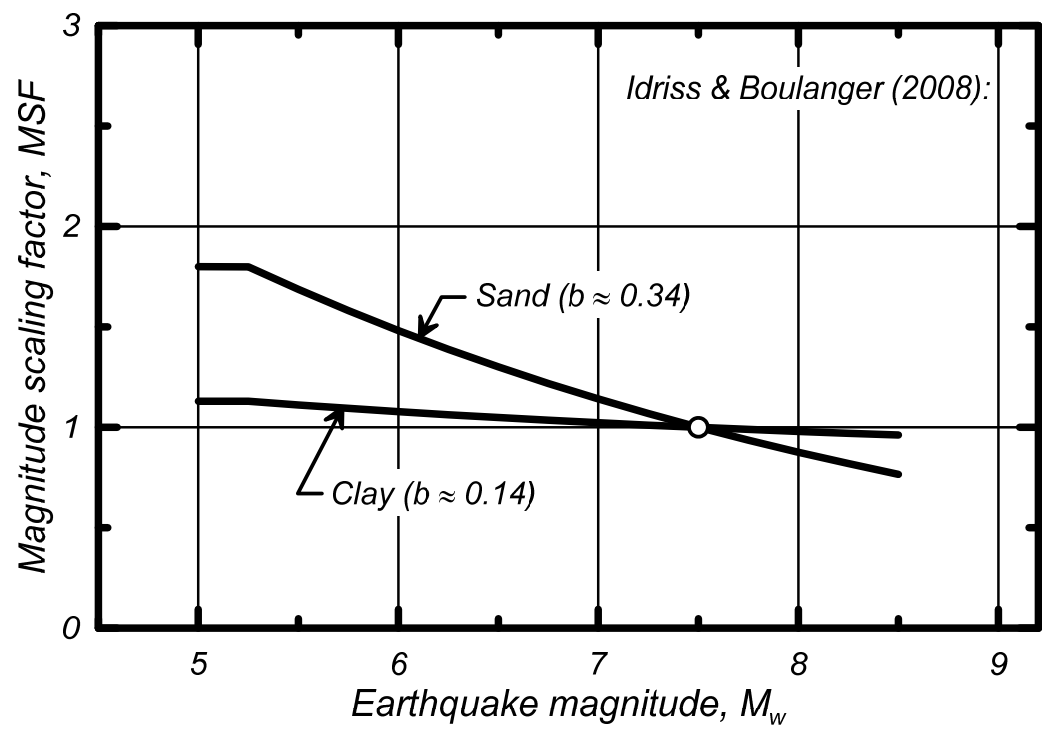

Fig. 1. MSF relationships for clay and sand (Boulanger and Idriss 2007)

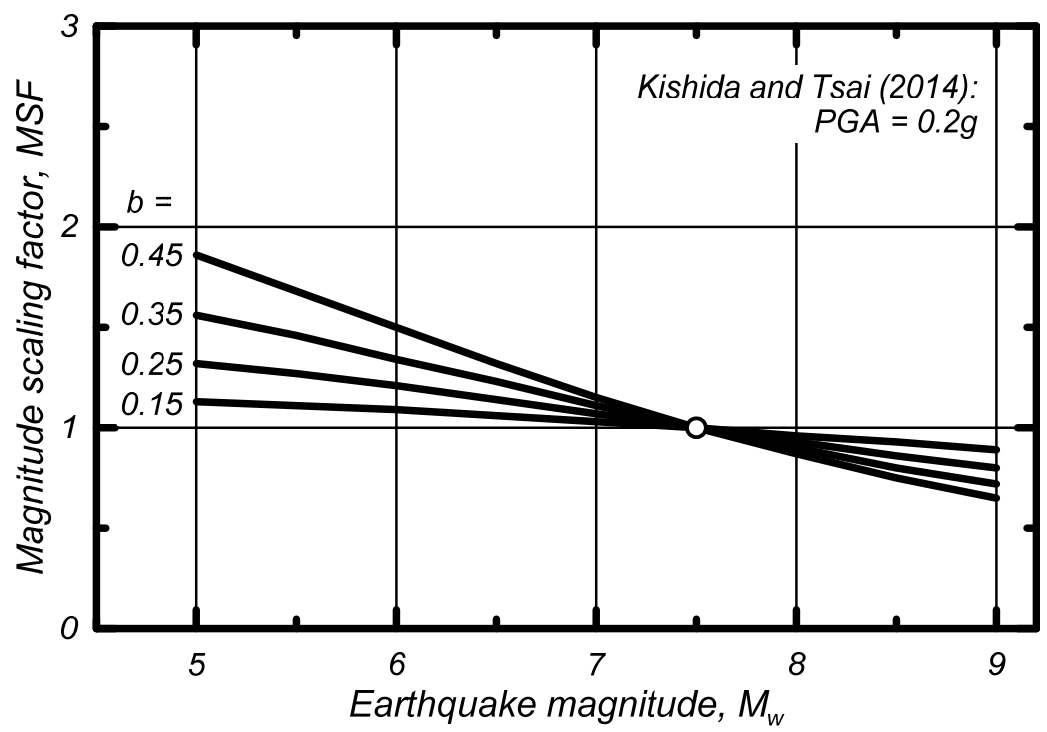

Fig. 2. MSF relationships by Kishida and Tsai (2014) 


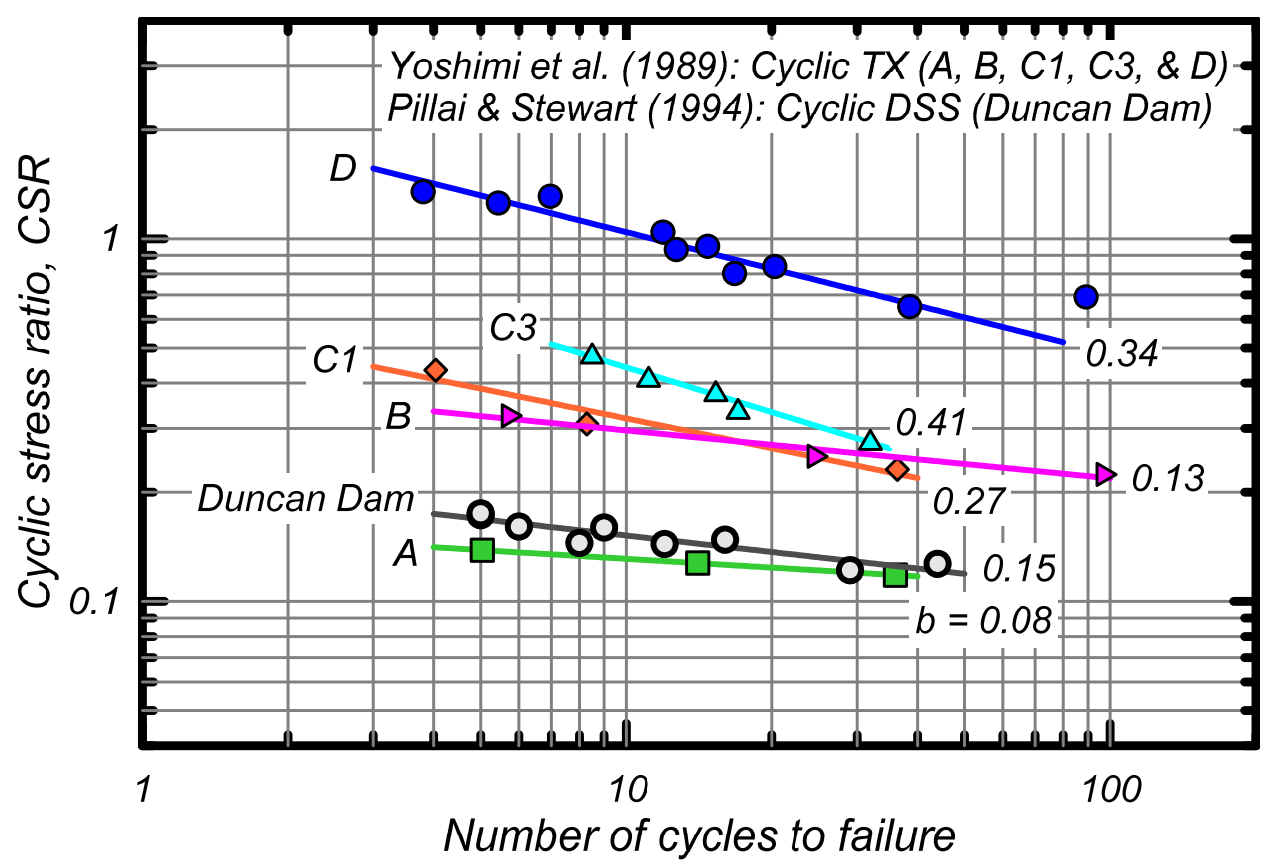

Fig. 3. Cyclic tests on sands obtained by frozen sampling techniques - triaxial data from Yoshimi et al. (1989) for 5\% double-amplitude axial strain and direct simple shear data from Pillai and Stewart (1994) for 4\% single-amplitude shear strain.

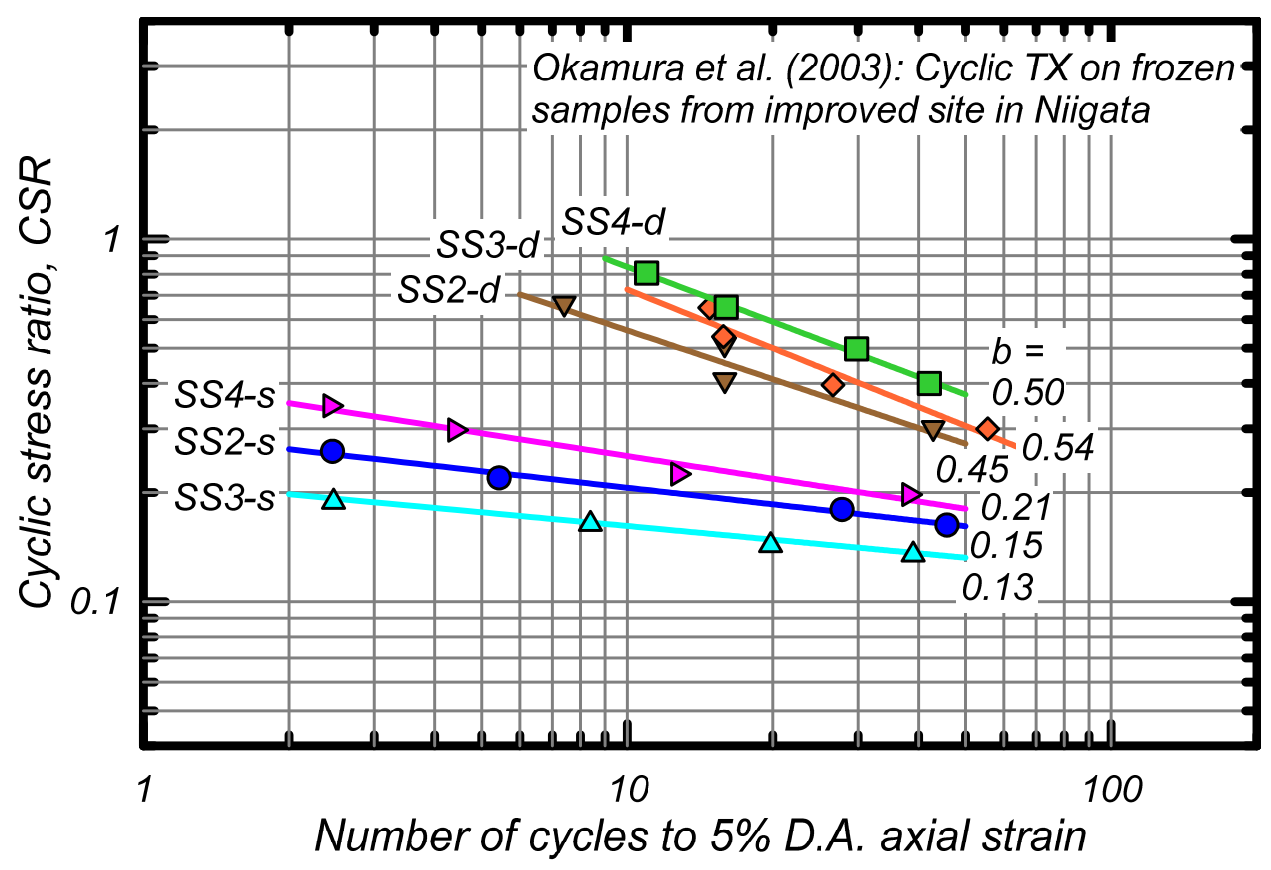

Fig. 4. Cyclic tests on sands obtained by frozen sampling techniques - data from Okamura et al. (2003) 


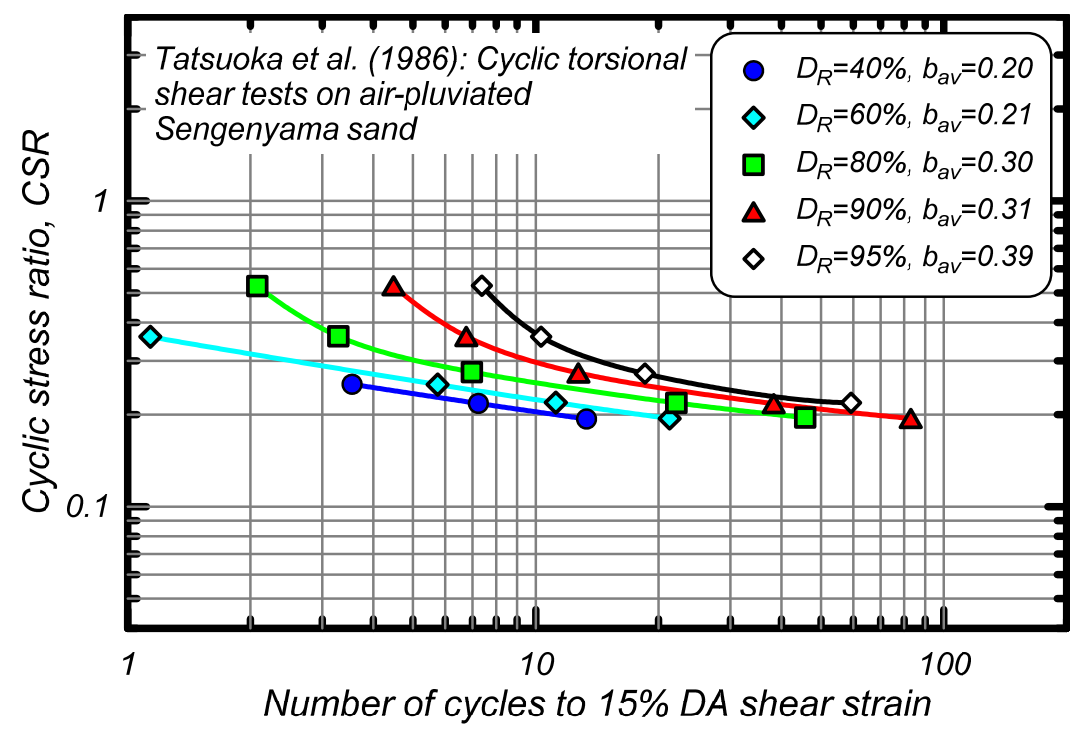

Fig. 5. Cyclic stress ratio to cause 15\% double-amplitude shear strain in anisotropicallyconsolidated cyclic undrained torsional shear tests (after Tatsuoka et al. 1986)
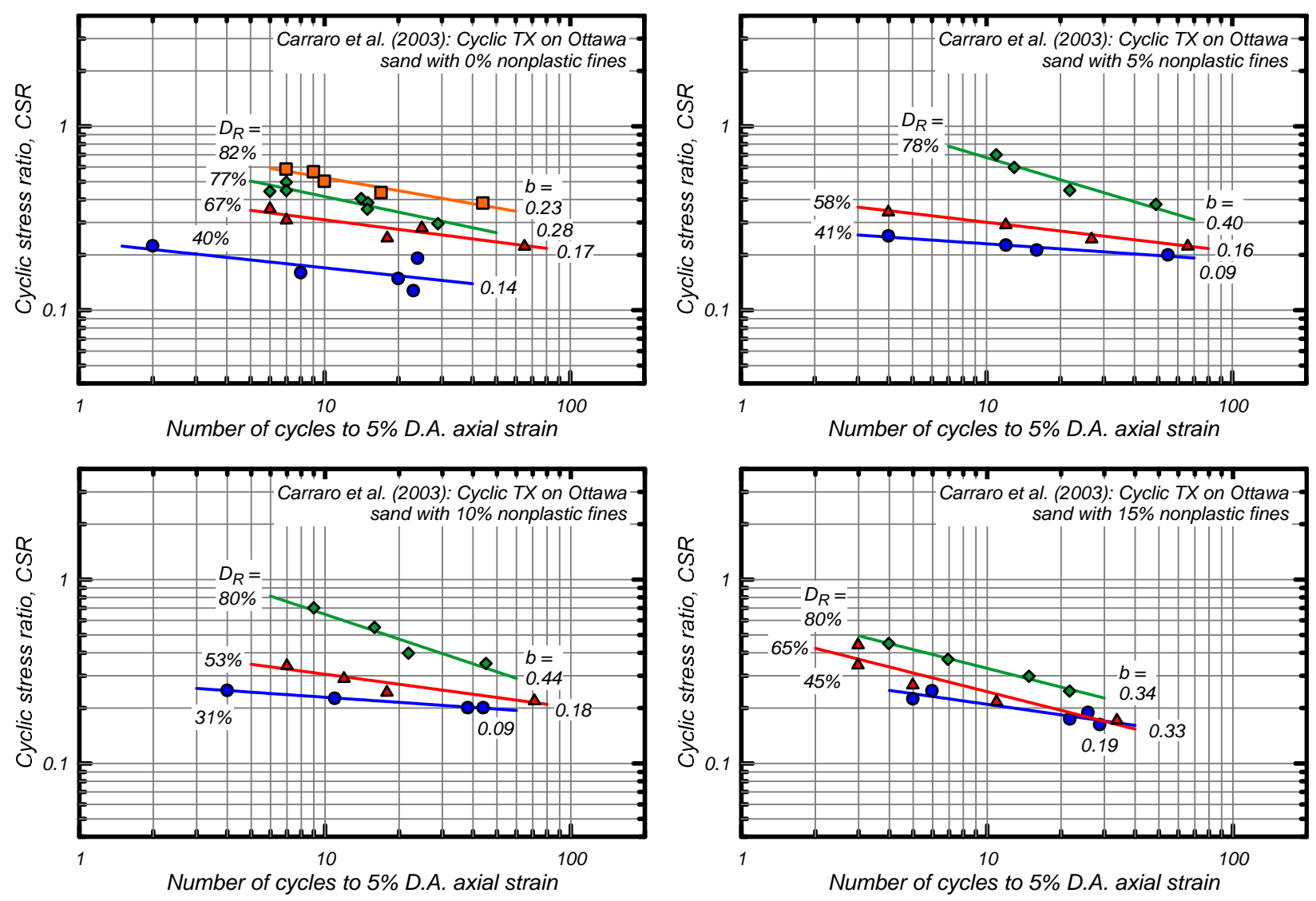

Fig. 6. Cyclic stress ratio to cause 5\% double-amplitude shear strain for Ottawa sand with 0,5, 10, and 15\% nonplastic fines (after Carraro et al. 2003) 


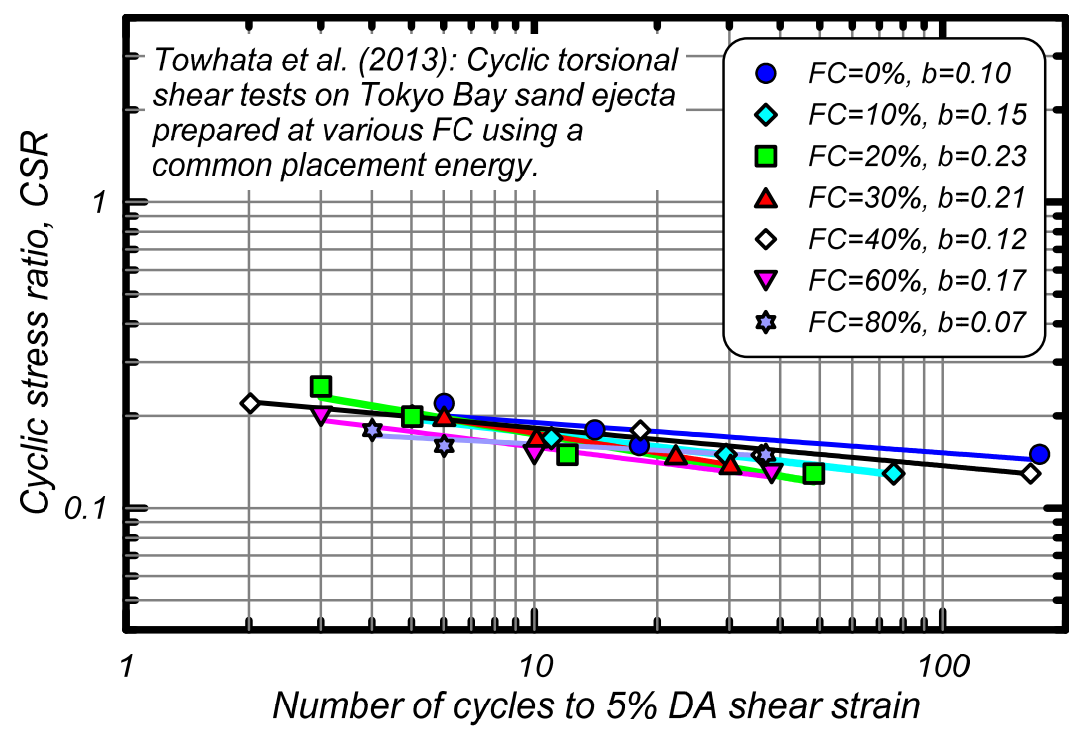

Fig. 7. Cyclic stress ratio to cause 5\% double-amplitude shear strain for Tokyo Bay sand ejecta with $0-80 \%$ nonplastic fines (after Towhata et al. 2013)

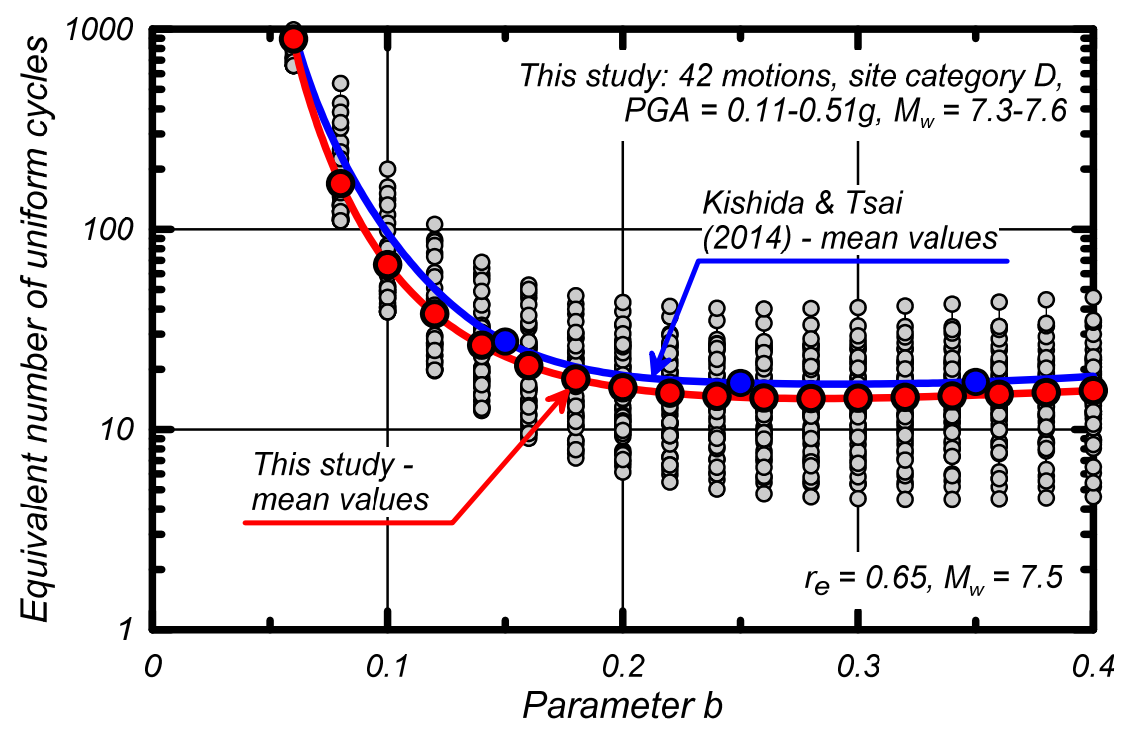

Fig. 8. Variation in number of equivalent uniform cycles with parameter $b$ for $M \approx 7.5$ 


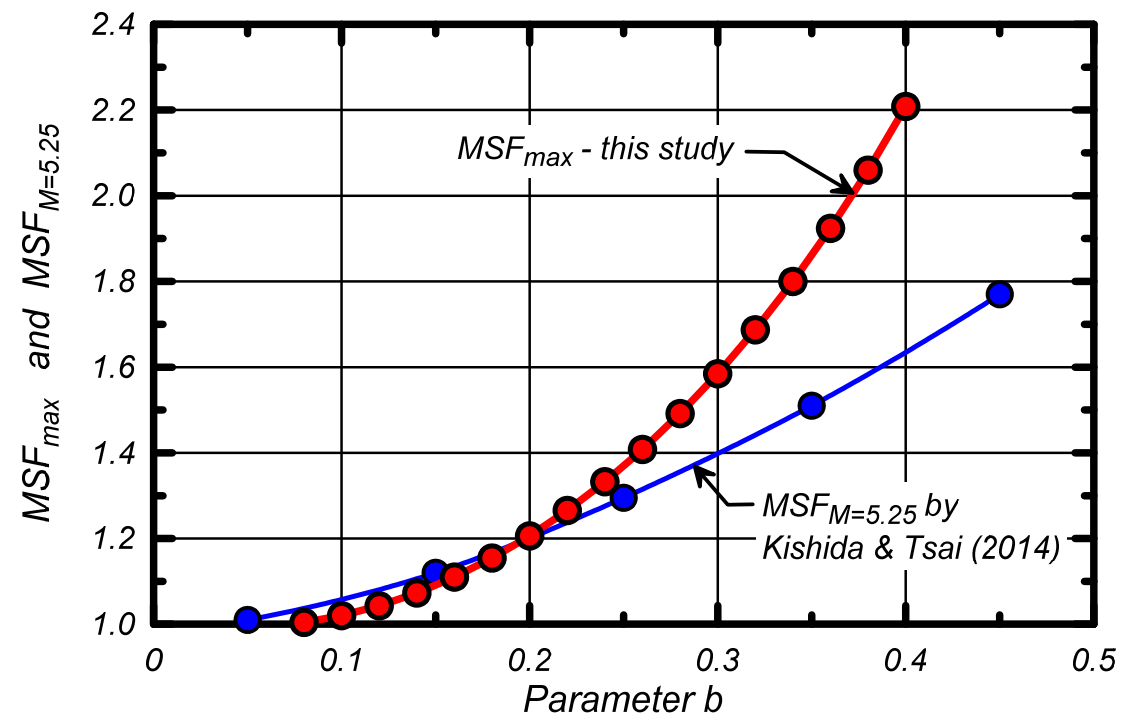

Fig. 9. Variation of $\mathrm{MSF}_{\max }$ with parameter $\mathrm{b}$

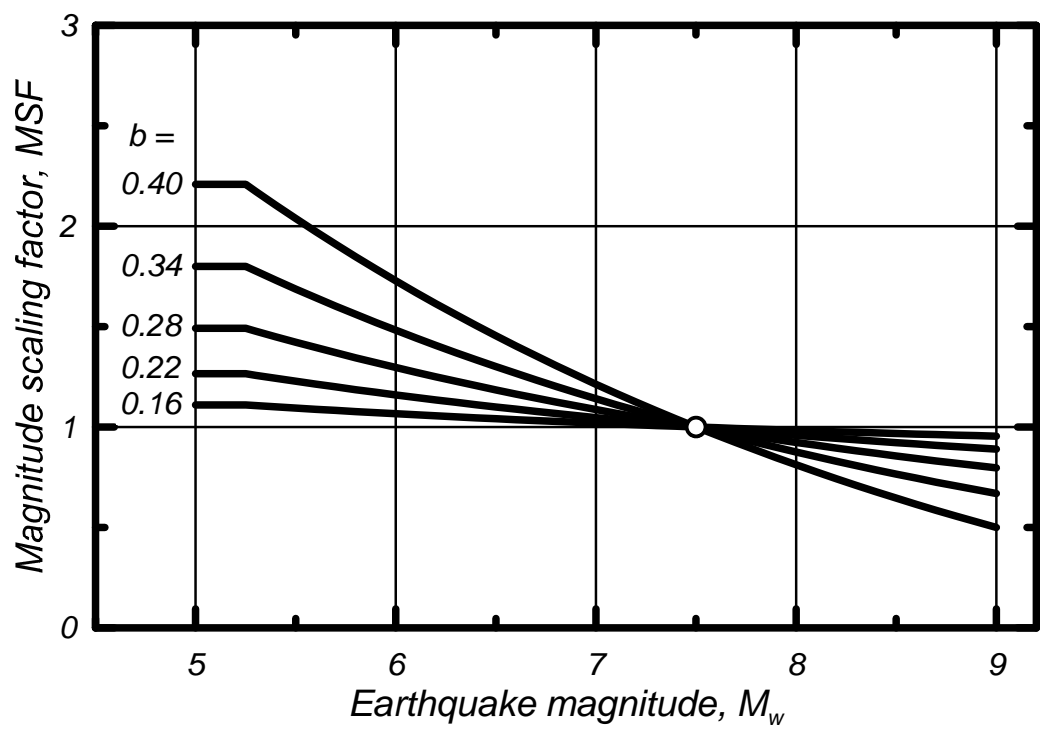

Fig. 10. Variation in the MSF relationship with parameter $b$ 


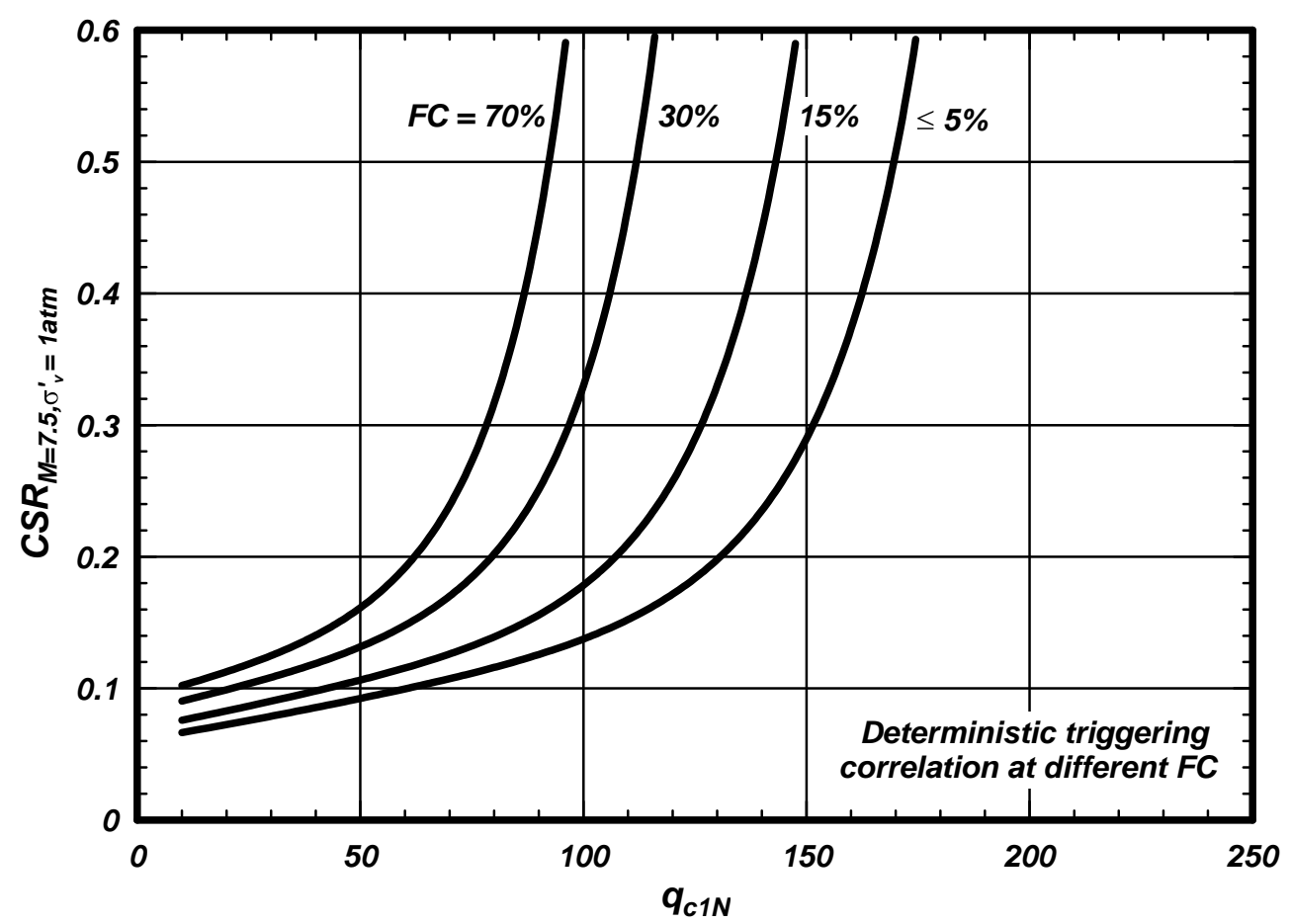

Fig. 11. Deterministic CPT-based triggering correlation for cohesionless soils at various fines contents (Boulanger and Idriss 2014).

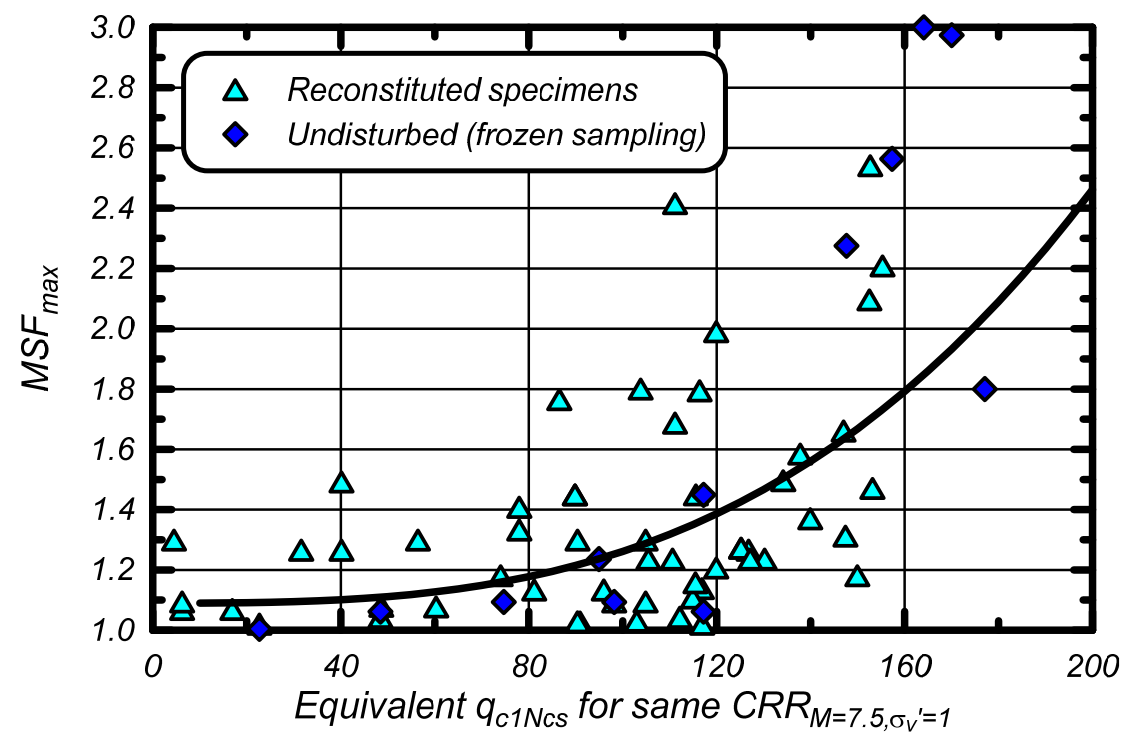

Fig. 12. Variation in $\mathrm{MSF}_{\max }$ with equivalent $\mathrm{q}_{\mathrm{c} 1 \mathrm{Ncs}}$ for cohesionless soils, with the proposed curve based on Equation 9. 


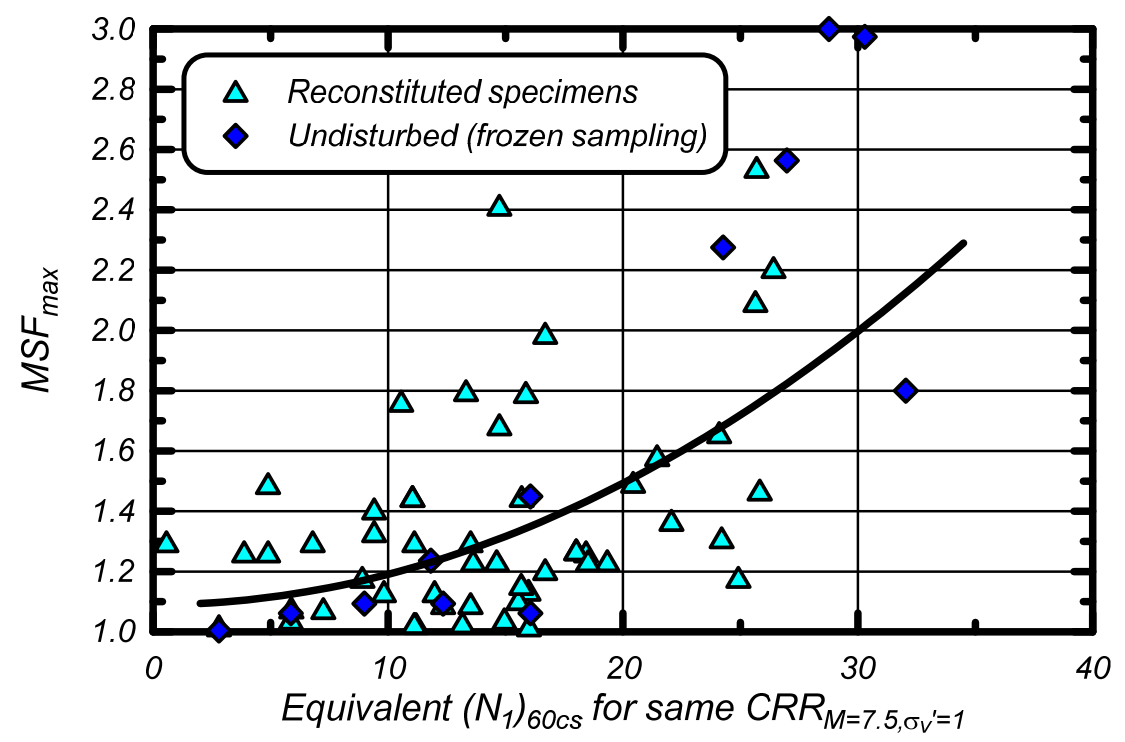

Fig. 13. Variation in $\mathrm{MSF}_{\max }$ with equivalent $\left(\mathrm{N}_{1}\right)_{60 \mathrm{cs}}$ for cohesionless soils, with the proposed curve based on Equation 10.

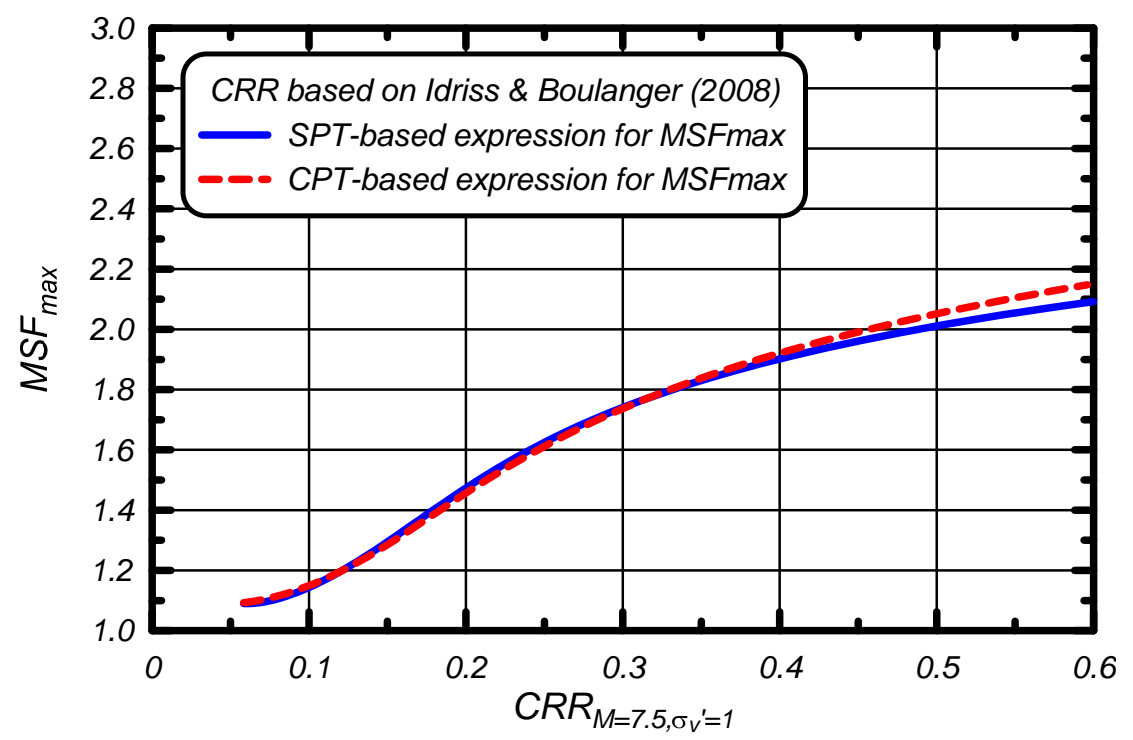

Fig. 14. Comparison of the SPT- and CPT-based equations for MSF max $_{\max }$ 


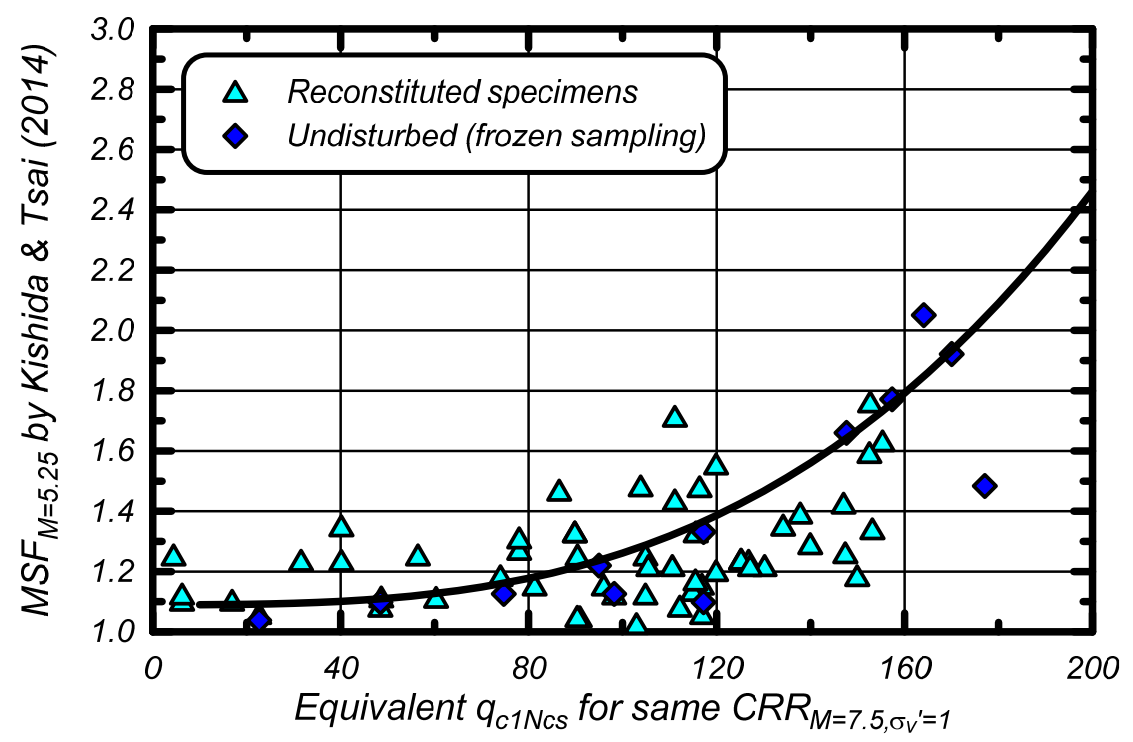

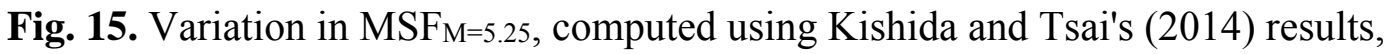
with equivalent $\mathrm{q}_{\mathrm{c} 1 \mathrm{Ncs}}$ for cohesionless soils and the proposed curve based on Equation 9.

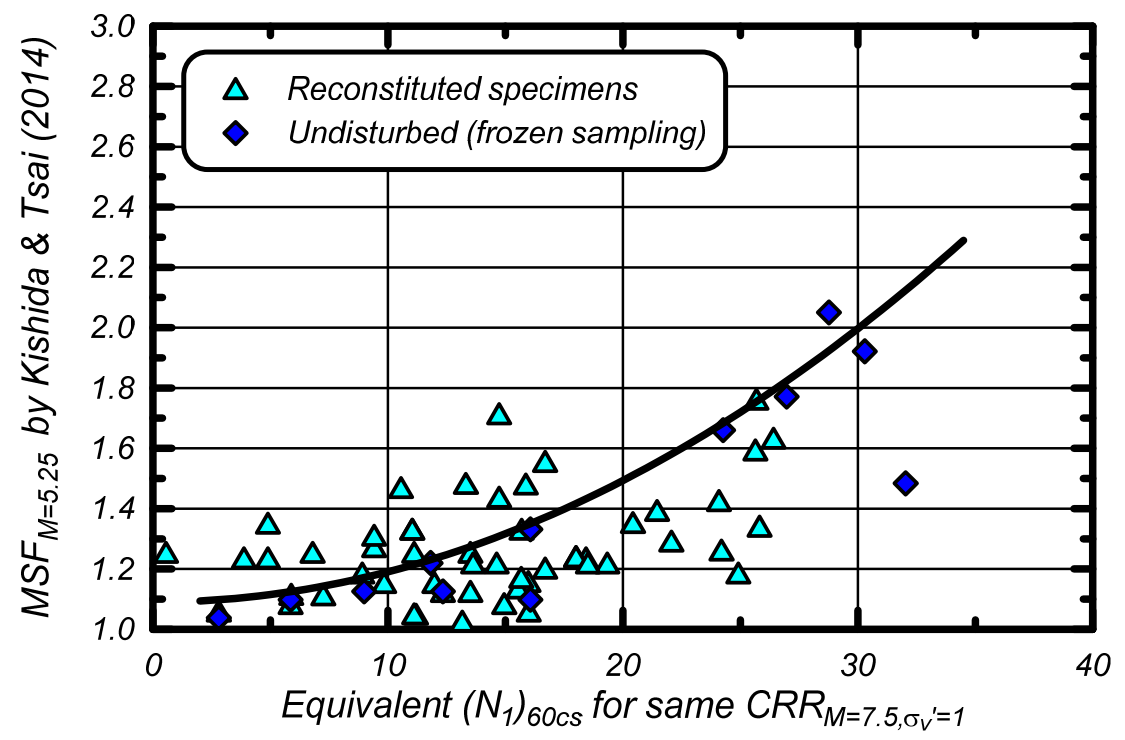

Fig. 16. Variation in $\mathrm{MSF}_{M=5.25}$, computed using Kishida and Tsai's (2014) results, with equivalent $\left(\mathrm{N}_{1}\right)_{60 \mathrm{cs}}$ for cohesionless soils and the proposed curve based on Equation 10 . 


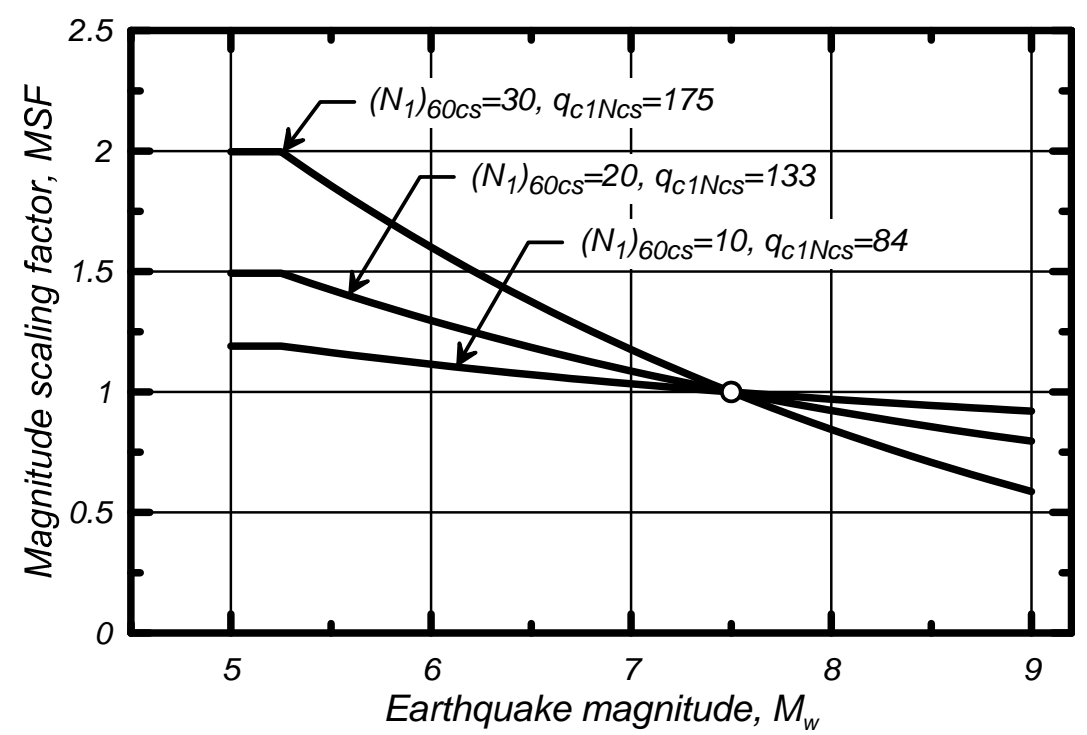

Fig. 17. Variation in the MSF relationship with $\mathrm{q}_{\mathrm{c} 1 \mathrm{Ncs}}$ and $\left(\mathrm{N}_{1}\right)_{60 \mathrm{cs}}$ for cohesionless soils

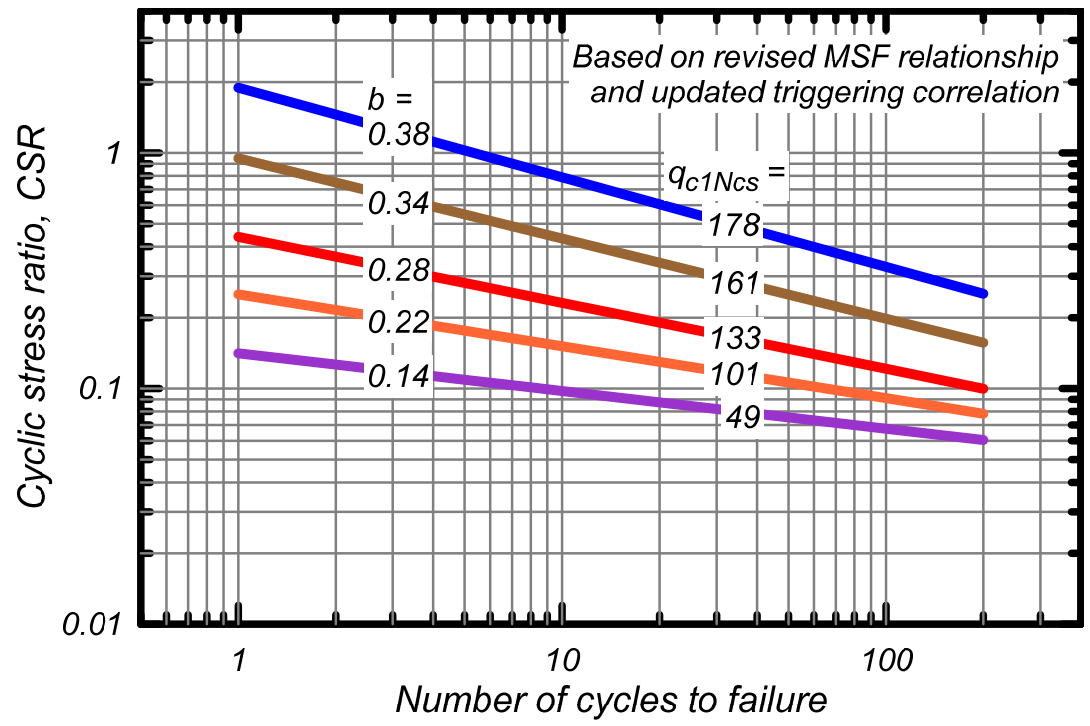

Fig. 18. Variation in CRR versus number of cycles based on the updated triggering correlation and the revised MSF relationship 